\title{
Oesophageal Foreign Bodies in Children
}

\author{
Pokharel R, ${ }^{1}$ Adhikari P,' Bhusal CL, ${ }^{1}$ Guragain RPS' \\ 'Department of ENT and Head and Neck Surgery, TU Teaching Hospital, Kathmandu, Nepal
}

\section{ABSTRACT}

Foreign body ingestion is a common occurrence and carries significant morbidity and mortality. Failure to treat foreign bodies immediately can lead to various serious complications. This study was done to identify the types as well as site of foreign body ingested and its complication in children.

A retrospective study of 122 cases of suspected foreign body ingestion in patients admitted in ENT and Head and Neck Surgery of TU Teaching Hospital, Kathmandu were done in between April 2004 to July 2008. Ages less than 12 years were included. In all cases x-ray soft tissue neck lateral and chest $x$-ray posterio-anterior views were done along with other preoperative investigations. Rigid oesophagoscopy or hypopharyngoscopy were done under general anesthesia to remove foreign bodies.

There were $64.7 \%$ male and $35.3 \%$ female children. Foreign bodies were common in $0-4$ year age group. Most common foreign body were coin (64.0\%) followed by meat bone $(14.0 \%)$. No foreign bodies were found in $2.4 \%$ patients as they were passed in stomach. No complications were noted during the entire period of this study.

Most common foreign bodies in children are coin. Though complications with these foreign bodies are rare, these do occur due to delay in presentation and removal. No complications were noted in our series. Eventhough children who swallow foreign bodies are asymptomatic; we must maintain a high index of suspicion and undergo diagnostic procedure, if there is a positive history.

Key words: foreign bodies, oesophagus, rigid oesophagoscopy

\section{INTRODUCTION}

Foreign body ingestion is a common occurrence and carries significant morbidity and mortality. ${ }^{1}$ The increased incidence of swallowing foreign bodies in children could be due to their natural propensity to gain knowledge by putting things in their mouth, inability to masticate well and inadequate control of deglutination as well as tendency to cry, cough or play during eating.
The habit of children putting things in the mouth makes them more susceptible to accidental ingestion. The most frequently swallowed foreign body in children includes coin, metallic foreign body (parts of playing objects). ${ }^{2-5}$ The peak age in children is between six months to three years. ${ }^{6}$ Failure to treat foreign bodies immediately can cause complications such as retropharyngeal abscess, retropharyngeal perforation, ulcerative oesophagitis, oesophago-respiratory fistula, recurrent pneumonitis,

\author{
Correspondence: \\ Dr. Prakash Adhikari \\ Department of ENT and Head and Neck Surgery \\ TU Teaching Hospital, Kathmandu, Nepal. \\ Email: prakash_ooz@hotmail.com
}


Adhikari et al. Oesophageal Foreign Bodies in Children

stricture formation, and impaction. ${ }^{5}$ This study was done to identify the types as well as site of foreign body ingested and its complication in children.

\section{MATERIAL AND METHODS}

This is a retrospective study of 122 cases of suspected foreign body ingestion in patients admitted in ENTHead and Neck Surgery department of TU Teaching Hospital, Kathmandu in between April 2004 to July 2008. Children less than 12 years of age were included. After the institutional approval data were collected. In all cases $x$-ray soft tissue neck lateral and chest $x$-ray posterio-anterior views were done along with other preoperative investigations. Rigid oesophagoscopy or hypopharyngoscopy were done under general anesthesia to remove foreign bodies Statistical analysis was done by simple manual analysis using frequency and percentage.

\section{RESULT}

This is a retrospective study of 122 cases of suspected foreign body ingestion in patients admitted in ENTHead and Neck Surgery department of TU Teaching Hospital, Kathmandu in between April 2004 to July 2008. Children less than 12 years of age were included. After the institutional approval data were collected. In all cases $\mathrm{x}$-ray soft tissue neck lateral and chest $\mathrm{x}$-ray posterio-anterior views were done along with other preoperative investigations. Rigid oesophagoscopy or hypopharyngoscopy were done under general anesthesia to remove foreign bodies Statistical analysis was done by simple manual analysis using frequency and percentage.

\section{DISCUSSION}

Swallowed foreign bodies are a common problem. Most frequently it is small children who ingest small items accidentally but other groups for example are mentally ill patients, prisoners and individuals who are attempting to conceal items such as drugs, may also occasionally be present. ${ }^{1}$

Foreign bodies are more common in children less than four years of age. But the peak age is between six months to three years. ${ }^{6}$ Our study showed that foreign bodies were common in $0-4$ years of age. Foreign bodies were more common in male children compared to female. However this study does not explain the high incidence of foreign bodies in male children. A possible explanation provided by Gupta et al is that male children are by nature more curious than female children. ${ }^{7}$

Most common foreign bodies in padeiatric age group are coins, but meat bone, marbles, safety pins, hair clips, batteries and screws are also reported. ${ }^{2-5,8-10}$ This study also showed coins to be the most common foreign body in children followed by meat bone $(14.0 \%)$ and metallic foreign bodies $(9.0 \%)$ which was in accordance with the study done by Adhikari et al.

Removal of a foreign body is not an easy task. ${ }^{1}$ The majority of ingested foreign bodies pass spontaneously but serious complications such as bowel perforation

Table 1. Age and distribution of foreign bodies in children

\begin{tabular}{llll}
\hline Age group & Male Number (Percentage) & Female Number (Percentage) & Total Number (Percentage) \\
\hline 0-4 years & $58(73.4 \%)$ & $26(60.5 \%)$ & $84(68.8 \%)$ \\
$5-8$ years & $16(20.3 \%)$ & $9(20.9 \%)$ & $25(20.5 \%)$ \\
$9-12$ years & $5(6.3 \%)$ & $8(18.6 \%)$ & $13(10.7 \%)$ \\
Total & $79(100.0 \%)$ & $43(100.0 \%)$ & $122(100.0 \%)$ \\
\hline
\end{tabular}

Table 2.Types of foreign bodies

\begin{tabular}{ll}
\hline Types of foreign body & Number (Percentage) \\
\hline Coin & $78(64.0 \%)$ \\
Meat bone & $17(14.0 \%)$ \\
Metallic foreign body & $11(9.0 \%)$ \\
Vegetative foreign body & $5(4.1 \%)$ \\
Battery & $5(4.1 \%)$ \\
Electric foreign body & $3(2.4 \%)$ \\
No foreign body found & $3(2.4 \%)$ \\
Total & $\mathbf{1 2 2 ( 1 0 0 \% )}$ \\
\hline
\end{tabular}

and obstruction can also occur. Foreign body in oesophagus blunt or sharp may be considered as an emergency as for fear of serious complications. These include intramural perforation, sub acute mediastinitis, aortooesophageal fistula, tracheooesophageal fistula, and long term residual injury to the oesophagus. ${ }^{11}$

In all of our patients, rigid oesophagoscopy or hypopharyngoscopy was done to remove foreign bodies. In $2.4 \%$ children, foreign bodies were not found during oesophagoscopy as they have gone down into the stomach. There were no complications noted in our series. Cricopharyngeal and Oesophageal foreign bodies are potentially hazardous and may pose problems regarding their diagnoses and management. 


\section{CONCLUSION}

Most common foreign bodies in children are coin. Though complications with these foreign bodies are rare, these do occur due to delay in presentation and removal. No complications were noted in our series. Eventhough children who swallow foreign bodies are asymptomatic; we must maintain a high index of suspicion and undergo diagnostic procedure, if there is a positive history.

\section{REFERENCES}

1. Adhikari P, Shrestha BL, Baskota DK, Sinha BK. Accidental foreign body ingestion: Analysis of 163 cases. Int Arch Otorhinolaryngol 2007;11:267-70.

2. Nandi P, Ong GB. Foreign body in the oesophagus: review of 2394 cases. Br J Surg 1978;65:5-9.

3. Guitron A, Adalid R, Huerta F, Macias M, Sanchez Navarrete M, Nares J.Extraction of foreign bodies in the esophagus. Experience in 215 cases. Rev Gastroenterol Mex 1996;61:1926.

4. Yang CY. The management of ingested foreign bodies in the upper digestive tract: a retrospective study of 49 cases. Singapore Med J 1991;32:312-5.

5. Nayak SR,Kirtane MV,Shah AK,KArnik PP. Foreign bodies in the cricopharyngeal region and oesophagus (a review of 226 cases). J Postgrad Med 1984;30:214-8.
6. Brown DA, Clark CM. Inhaled foreign bodies in children. Med J Aust 1983;2:322-6.

7. Gupta A, Chopra K, Saha M, Khanna SK, Gupta RK, Narayan PS and Sharma S. Foreign bodies in the tracheobronchial tree. Indian Paediatrics 1977;14:133-4

8. Hansen LT, Grontved A. Foreign body in the oesophagus. Ugeskr Laeger 1994;156:4333-5.

9. Giordano A, Adams G, Boies L Jr, Meyerhoff W. Current management of esophageal foreign boides. Arch Otolaryngol 1981;107:249-51.

10. Morales Angulo C, Rodriguez Iglesias J, Mazon Gutierrez A, Gomez Castellano R, Rama J. Foreign bodies in the esophagus. Acta Otorrinolaryngol Esp 1998;49:644-6.

11. Jona JZ, Glicklich M, Cohen RD. The contraindications for blind esophageal bouginage for coin ingestion in children. J Pediatr Surg 1988;23:328-30. 